\title{
Validasi Data Curah Hujan Satelit TRMM (Tropical Rainfall Measuring Mission) dengan Data Pos Penakar Hujan di DAS Grindulu, Kabupaten Pacitan, Jawa Timur
}

\author{
Dieta Putri Jarwanti $^{1 *}$, Ery Suhartanto ${ }^{1}$, Jadfan Sidqi Fidari ${ }^{1}$ \\ ${ }^{1}$ Jurusan Teknik Pengairan, Fakultas Teknik, Universitas Brawijaya, \\ Jalan MT. Haryono No. 167, Malang, 65145, INDONESIA \\ *Korespondensi Email: dietaptr@gmail.com
}

\begin{abstract}
Ground stations in Indonesia aren't evenly distributed, whereas the resulted rainfall data is important. Then validation analysis with TRMM satellite data is required because it can cover a wide area, near realtime availability and fast access. This research aims to validate satellite data with observation data in the Grindulu watershed. Later, used to anticipate observation rainfall data that may be an error or unavailable. Validation methods used are Root Mean Squared Error (RMSE), Relative Error (RE), Nash Sutcliffe-Efficiency (NSE), and Correlation Coefficient (R). This research was done with two steps, those were TRMM data uncorrected and corrected, where the corrected data was done by calibration first. It showed that the best corrected TRMM data were found in a monthly period with a range of nine years of calibration in couple with one year of validation have a value of $\mathrm{NSE}=0.929 ; \mathrm{R}=0.969 ; \mathrm{RMSE}=$ 46.48 and $\mathrm{RE}=8.9 \%$. So, it showed that corrected TRMM data resulted have a better value than uncorrected data because the NSE and R values approaching one and have small values of RMSE and Relative Error. Overall, TRMM Satellite data can be used as an alternative hydrology data in the Grindulu watershed.
\end{abstract}

Keywords: calibration, ground station, rainfall, TRMM, validation

\begin{abstract}
Abstrak: Pos penakar hujan di Indonesia lokasinya masih kurang tersebar merata, padahal data hujan yang dihasilkan sangat penting. Maka diperlukan analisis validasi dengan data satelit TRMM karena dapat mencakup wilayah luas, tersedia secara near real-time dan aksesnya yang cepat. Penelitian ini bertujuan untuk memvalidasi data satelit dengan data observasi di DAS Grindulu yang datanya dianggap lengkap dan dapat diandalkan. Nantinya digunakan untuk mengantisipasi data curah hujan observasi yang mungkin error atau tidak tersedia. Metode validasi yang digunakan berupa Root Mean Squared Error (RMSE), Uji Kesalahan
\end{abstract}


Relatif (KR), Nash Sutcliffe Efficiency (NSE) serta Koefisien Korelasi (R). Penelitian ini menggunakan dua tahap perhitungan, yaitu analisis validasi data tidak terkoreksi dan data terkoreksi, dimana data terkoreksi dilakukan kalibrasi data terlebih dahulu, hasil dari validasi data TRMM terkoreksi terbaik terdapat pada periode bulanan dengan rentang kalibrasi 9 tahun dan validasi 1 tahun dengan hasil $\mathrm{NSE}=0,929 ; \mathrm{R}=0,969 ; \mathrm{RMSE}=46,48 ; \mathrm{KR}$ $=8,9 \%$. Hasil tersebut menunjukkan bahwa data TRMM terkoreksi menghasilkan nilai yang lebih baik dibandingan data TRMM tidak terkoreksi karena memiliki nilai NSE dan R yang mendekati satu dan nilai RMSE dan Kesalahan Relatifnya rendah. Secara kesluruhan, dapat disimpulkan bahwa data TRMM dapat digunakan sebagai data alternatif hidrologi di DAS Grindulu.

Kata kunci: curah hujan, kalibrasi, pos penakar hujan, TRMM, validasi

\section{Pendahuluan}

Informasi kualitas dan kuantitas data curah hujan dalam bidang sumber daya air sangat penting, karena data hujan yang akurat akan digunakan oleh instansi terkait untuk merumuskan kebijakan, strategi dan rencana tata air. Pada kenyataannya, sangat sulit dalam mendapatkan data curah hujan yang baik kualitas dan kuantitasnya karena keterbatasan dari alat penakar hujan terutama di daerah terpencil dan kurang tersebar meratanya alat tersebut sehingga sulit untuk melakukan penelitian dan analisis sumber daya air berdasarkan dari data curah hujan, karena memang banyak tempat yang belum memiliki penakar penakar hujan [1].

Permasalahan tersebut terjadi di DAS Grindulu, DAS tersebut mempunyai luas sebesar $645,242 \mathrm{~km}^{2}$ namun hanya tersedia satu penakar hujan di dalamnya, yaitu Penakar Nawangan Grindulu. Hal tersebut tentunya tidak sesuai dengan ketentuan dari Badan Meteorologi Dunia atau World Meteorogical Organization (WMO) yang telah memberikan pedoman tentang kerapatan jaringan penakar hujan pada wilayah bergunung dengan zona sedang seperti wilayah DAS Grindulu idealnya satu penakar hujan setidaknya mencakup wilayah $100-250 \mathrm{~km}^{2}$. Hal tersebut membuat kondisi dari Stasiun Nawangan Grindulu sebagai satu-satunya penakar yang berada di wilayah DAS Grindulu tidak dapat mewakili DAS tersebut yang nantinya dapat mempengaruhi akurasi dari data curah hujan.

Dengan terus berkembangnya teknologi penginderaan jauh seperti radar dan satelit, sekarang dimungkinkan untuk menggunakan teknologi tersebut untuk mengukur curah hujan sebab teknologi tersebut dapat menjangkau tempat-tempat yang belum bisa dijangkau oleh penakar curah hujan konvensional, lalu curah hujan dapat dipantau dalam skala besar. Khusus untuk daerah tropis seperti Indonesia, kini sudah ada perangkat penginderaan jauh yang dapat menggunakan satelit TRMM atau Tropical Rainfall Measurement Mission untuk misi pengukuran curah hujan [2].

Data hujan TRMM dapat dikatakan sangat berguna dalam perencanaan khususnya pada bidang keairan. Namun faktanya, data TRMM belum divalidasi secara luas dengan data hujan lapangan. Sehingga data TRMM belum bisa untuk langsung digunakan dalam kajian maupun analisis sumberdaya air [1]. Sehingga dirasa perlu untuk dilakukan analisis validasi antara data hujan TRMM dengan data hujan dari pos penakar hujan. 
Belum ada studi-studi terdahulu yang memvalidasi data hujan dari Satelit TRMM dengan data pos penakar hujan di DAS Grindulu. Untungnya, pada DAS Grindulu walaupun hanya terdapat satu pos penakar hujan yang berada di dalamnya, namun terdapat dua penakar di luar DAS tersebut, Penakar Pacitan dan Penakar Kebonagung, yang lokasinya cukup dekat dengan DAS sehingga dirasa masih memberikan pengaruh terhadap DAS tersebut. Ketiga penakar tersebut saat ini memiliki data yang cukup panjang dan lengkap. sehingga dirasa dapat merepresentasikan DAS Grindulu untuk dilakukan analisis validasi dengan data hujan satelit TRMM. Dengan demikian, hasil validasi yang didapatkan besar harapannya dapat menjadi acuan dalam pengembangan data TRMM yang dapat digunakan di Indonesia dan dapat memenuhi kebutuhan dalam pengembangan DAS Grindulu di masa mendatang jika suatu saat terjadi permasalahan data hujan.

\section{Bahan dan Metode}

\subsection{Bahan}

\subsubsection{Lokasi Studi}

Secara geografis DAS Grindulu, terletak di antara $7^{\circ} 55^{\prime} 56.18^{\prime \prime}$ - $8^{\circ} 14^{\prime} 39.5746^{\prime \prime}$ LS dan $111^{\circ} 02^{\prime} 34.0013^{\prime \prime}-111^{\circ} 24^{\prime} 39.4553^{\prime \prime}$ BT. Secara administratif, terletak di Jawa Timur dan Jawa Tengah secara spesifik berada di antara tiga wilayah yakni Kabupaten Ponorogo, Kabupaten Wonogiri, dan yang paling luas yaitu Kabupaten Pacitan karena hampir 90,6\% atau seluas 593,8 $\mathrm{km}^{2}$ luas DAS Grindulu termasuk wilayah dari Kabupaten Pacitan.

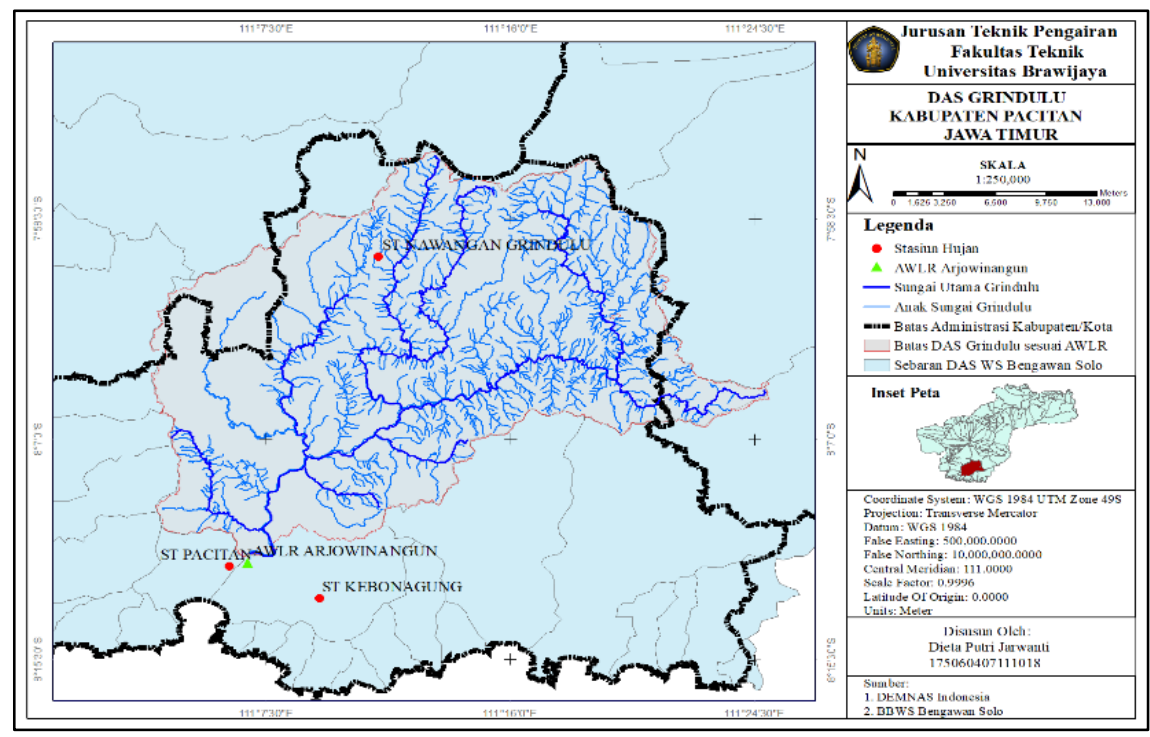

\section{Gambar 1: Batas DAS Grindulu dan Sebaran Pos Penakar Hujan Daerah Studi}

\subsubsection{Data Penelitian:}

Berikut ini merupakan data-data yang diperlukan:

1. Koordinat pos penakar hujan.

2. DEM, peta jaringan sungai, serta peta topografi.

3. Data curah hujan harian tiga pos penakar hujan sepanjang sepuluh tahun (2010-2019).

4. Data curah hujan harian TRMM selama 10 tahun tipe TRMM_3B42RTv7 (20102019). 


\subsection{Metode}

Penelitian ini menggunakan metode validasi dari data hujan Satelit TRMM dengan data hujan pos penakar hujan selama 10 tahun menggunakan periode 10 harian, 15 harian serta bulanan. Penakar hujan yang terdapat pada wilayah DAS Grindulu, diantaranya Penakar Kebonagung, Pacitan, dan Nawangan Grindulu.

Dalam analisis data statistika, kualitas data yang baik sangat dibutuhkan terlebih lagi pada suatu data deret berkala (time series) seperti halnya data curah hujan, tujuannya adalah untuk menentukan kualitas suatu data sebab dalam proses pengambilan data di lapangan pastinya menghadapi berbagai gangguan dari aspek lingkungan yang tentunya dapat mempengaruhi data. Dalam studi ini, data curah hujan ground station dan TRMM dilakukan perhitungan uji kualitas data berupa uji konsistensi serta uji stasioner [3].

Data ground station dilakukan pengujian konsistensi berupa Kurva Massa Ganda sedangkan untuk data TRMM karena data tunggal digunakan metode RAPS. Data curah hujan pos penakar hujan terlebih dahulu ditranformasikan menjadi bentuk hujan rerata wilayah, metode hujan wilayah pada penelitian ini menggunakan Polygon Thiessen karena data TRMM tipe TRMM_3B42RTv7 yang terunduh berbentuk grid atau hujan wilayah.

TRMM ialah satelit kerja sama antara Amerika serta Jepang yang tujuannya menyediakan kumpulan informasi yang rinci serta komprehensif dari distribusi curah hujan empat dimensi dan panas laten di lautan dan benua tropis serta subtropis yang kekurangan sampel [4]. Pada penelitian ini digunakan validasi data TRMM karena data tersebut memiliki beberapa keunggulan, seperti dapat mencakup wilayah yang tergolong cukup luas, memiliki kemampuan dalam melakukan pemetaan dari variasi curah hujan secara secara spasial maupun secara temporal yang besar serta resolusi spasialnya sampai dengan $0,25^{\circ}$ (setara dengan $27 \mathrm{~km}$ ) [5]. Keunggulan data TRMM lainnya adalah tersedia secara near real time, ter-update setiap 3 jam sekali, konsisten, dan dapat diakses secara gratis serta mudah [6]. Namun, data TRMM perlu dievaluasi karena data satelit pada dasarnya mengukur besar hujan yang ada di atmosfer, sedangkan data hujan pos penakar hujan adalah mengukur besar hujan yang terjadi di lapangan [7]. Selain itu, data TRMM menggunakan infrared dan radiasi gelombang mikro untuk mengukur curah hujan yang kadang kala gelombang mikro tersebut terganggu oleh sesuatu di atmosfer [8].

Dikarenakan kelemahan dari data TRMM tersebut maka perlu analisis validasi data TRMM, pada penelitian ini analisis validasi dilakukan dengan membaginya menjadi dua tahapan, terdiri dari tahap analisis validasi data tidak terkoreksi dan data terkoreksi. Perbedaannya adalah data TRMM tidak terkoreksi dilakukan perbandingan antara data curah hujan pos penakar hujan dengan data curah hujan Satelit TRMM tanpa melalui proses kalibrasi. Sementara itu, jika tahap validasi data terkoreksi, data curah hujan TRMM dilakukan koreksi terlebih dahulu berupa proses kalibrasi dengan data pos penakar hujan yang kemudian dilakukan validasi. Pada data terkoreksi digunakan komposisi tahun kalibrasi dan validasi, yaitu 7:3, 8:2, dan 9:1 yang artinya adalah 7 tahun (2010 - 2016) untuk proses kalibrasi dan 3 tahun (2017-2019) untuk proses validasi, sama halnya dengan arti dari perbandingan 8:2 dan 9:1.

Data dilakukan uji validasi dengan menggunakan empat metode, yaitu Root Mean Squared Error (RMSE), Uji Kesalahan Relatif (KR), Nash-Sutcliffe Efficiency (NSE), serta 
Koefisien Korelasi (R). Rentang data yang dipakai untuk analisis validasi data tidak terkoreksi yakni, sepuluh, tiga, dua, dan satu tahun. Maksud dari rentang data 10 tahun dilakukan uji validasi adalah untuk melihat hasil validasinya secara keseluruhan, apakah hasil tersebut menunjukkan performa dari data satelit dengan hasil yang baik atau tidak tanpa dilakukannya kalibrasi. Sementara itu, untuk rentang data 3 tahun, 2 tahun, serta 1 tahun pada uji validasi data TRMM tidak terkoreksi nantinya akan dibandingkan dengan hasil uji validasi pada data TRMM terkoreksi.

\subsubsection{Kalibrasi}

Kalibrasi model ialah proses dalam memilih kombinasi dari parameter, atau sama halnya sebagai proses dalam mengoptimalkan parameter agar meningkatkan koherensi antara respon hidrologi DAS yang teramati dalam hal ini adalah data pos penakar hujan dan tersimulasi dalam hal ini adalah data satelit TRMM [9].

Analisis kalibrasi curah hujan menggunakan persamaan regresi $y=f(x)$ yang terbentuk oleh hubungan curah hujan satelit sebagai variabel $\mathrm{x}$ dan curah hujan pengamatan sebagai variabel y yang menghasilkan persamaan koreksi curah hujan satelit [10].

Analisis regresi merupakan analisis yang membahas hubungan antara dua variabel atau lebih. Bila analisis regresi sudah menghasilkan model dalam bentuk persamaan matematis yang cocok, Langkah selanjutnya yaitu menentukan seberapa kuat hubungan yang terbentuk antara variabel-variabel tersebut atau harus ditentukan derajat hubungan (derajat asosiasi) diantara variabel hidrologi yang digunakan dalam analisis regresi. Dalam analisis regresi, terdapat analisis yang membahas mengenai derajat asosiasi, analisis tersebut disebut dengan analisis korelasi.

Derajat hubungan tersebut umumnya dinyatakan secara kuantitatif sebagai koefisien korelasi (correlotion coefficient) maka tepat untuk digunakan dalam penelitian ini karena ingin diketahui hubungan antara data TRMM dengan data penakar hujan apakah hubungannya sangat kuat sehingga nantinya dapat digunakan sebagai data alternatif hidrologi. Jika koefisien korelasinya tinggi tidak berarti memiliki kesamaan dalam kejadian fenomena hidrologi (hydrological similarity) akan tetapi cenderung menunjukkan bahwa terjadi kesamaan waktu kejadian dalam fenomena hidrologi (simultaneity of hydrological events) [11].

\subsubsection{Validasi}

Validasi ialah proses evaluasi dari suatu model agar memperoleh gambaran dari terkait tingkat ketidakpastian dari suatu model yang sudah dihasilkan dari proses kalibrasi untuk memprediksi proses hidrologi [12]. Biasanya validasi menggunakan data yang berada di luar periode data untuk kalibrasi [9]. Validasi data tujuannya adalah melihat seberapa besar akurasi dari data TRMM yang dapat menggambarkan curah hujan yang terjadi permukaan bumi [5].

Model validasi statistik dibedakan menjadi tiga katagori, yaitu model evaluasi statistik standar regresi dalam hal ini dilakukan perhitungan nilai koefisien korelasi (R), model evaluasi statistik tidak berdimensi dalam hal ini dilakukan perhitungan nilai Nash-Sutcliffe Efficiency (NSE), dan model evaluasi statistik indeks kesalahan dalam hal ini dilakukan perhitungan nilai Root Mean Squared Error (RMSE) serta Kesalahan Relatif (KR) [13]. 


\subsection{Persamaan}

\subsubsection{Kalibrasi}

Dalam analisis hidrologi model yang banyak digunakan adalah analisis regresi, dimana analisis tersebut dapat menghubungkan variabel satu dengan yang lainnya, biasanya terdiri dari dua variabel [14]. Berikut merupakan persamaan untuk membuat hubungan antara dua variabel, antara lain [11]:

a. Fungsi eksponensial (exponential regression)

$\widehat{\mathrm{Y}}=\mathrm{be}^{\mathrm{ax}}$

Pers. 1

Keterangan:

$\hat{\mathrm{Y}}=$ regresi eksponensial Y terhadap X (variabel tak bebas).

$\mathrm{X}=$ variabel bebas.

$\mathrm{b}=$ parameter.

$\mathrm{e} \quad=$ bilangan pokok logaritma asli (logaritma Napir $=2,7183$ ).

b. Linear sederhana (linear regression)

$\widehat{Y}=a_{1} X+b_{1}$

Pers. 2

$\widehat{\mathrm{X}}=\mathrm{a}_{2} \mathrm{Y}+\mathrm{b}_{2}$

Pers. 3

Keterangan:

$\hat{\mathrm{Y}} \quad=$ persamaan garis lurus $\mathrm{Y}$ terhadap $\mathrm{X}$.

$\widehat{\mathrm{X}} \quad=$ persamaan garis lurus $\mathrm{X}$ terhadap $\mathrm{Y}$.

$\mathrm{a}_{1}, \mathrm{a}_{2}=$ koef. regresi (koefisien arah dari garis regresi).

$b_{1}, b_{2}=$ koef. yang merupakan titik potong dari garis regresi.

c. Fungsi logaritma (logarithmic regression)

$\hat{\mathrm{Y}}=\mathrm{b}+\mathrm{a} \log \mathrm{X}$

Pers. 4

Keterangan:

$\hat{\mathrm{Y}}=$ regresi $\mathrm{Y}$ terhadap $\mathrm{X}$.

$\mathrm{X}=$ variabel bebas (harus lebih besar nol).

$\mathrm{a}, \mathrm{b}=$ parameter.

d. Fungsi polinomial (polynomial regression)

$\mathrm{Y}=\mathrm{b}_{\mathrm{o}}+\mathrm{b}_{1} \mathrm{X}+\mathrm{b}_{2} \mathrm{X}^{2}+\mathrm{b}_{3} \mathrm{X}^{3}+\ldots+\mathrm{b}_{\mathrm{m}} \mathrm{X}^{\mathrm{m}}$

Pers. 5

Keterangan:

$\mathrm{Y}=$ regresi $\mathrm{Y}$ terhadap $\mathrm{X}$.

$\mathrm{X}=$ variabel bebas.

$\mathrm{b}=$ parameter.

e. Fungsi berpangkat (power regression)

$\hat{\mathrm{Y}}=\mathrm{bX}^{\mathrm{a}}$

Pers. 6

Keterangan:

$\hat{Y}=$ regresi eksponensial $Y$ terhadap $X$.

$\mathrm{X}=$ variabel bebas.

Koherensi hasil dari kalibrasi dilihat menggunakan scatter plot atau diagram pencar dimana hasil yangkoefisien korelasinya paling tinggi menunjukkan koherensi yang paling baik [9]. Oleh karena itu, pemilihan jenis persamaan yang terpilih untuk mengkoreksi data didasarkan pada nilai $\mathrm{R}$ (koefisien korelasi) yang paling tinggi. 


\subsubsection{Validasi}

Validasi data tujuannya untuk melihat sejauh mana akurasi dari data TRMM apakah dapat untuk menggambarkan curah hujan permukaan [5]. Berikut merupakan beberapa indikator statistik untuk melakukan analisis validasi:

a. Nash-Sutcliffe Efficiency (NSE)

Metode ini menunjukkan seberapa besar ketelitian yang dihasilkan dari korelasi hubungan yang terbentuk antara data observasi serta data perkiraan. Metode ini juga menunjukan nilai apakah hasil plotnya semakin baik dari nilai observasi (data pengamatan) dibandingkan dengan nilai hasil dari prediksi-simulasi, apakah sesuai dengan garis 1:1 atau tidak, dengan rentang nilai $\infty$ ke 1 [15]. Sebuah model dapat dikatakan bagus jika menghasilkan nilai koefisien Nash mendekati satu [9].

$\mathrm{NSE}=1-\frac{\sum_{\mathrm{i}=1}^{\mathrm{N}}\left(\mathrm{P}_{\mathrm{i}}-\mathrm{Q}_{\mathrm{i}}\right)^{2}}{\sum_{\mathrm{i}=1}^{\mathrm{N}}\left(\mathrm{P}_{\mathrm{i}}-\overline{\mathrm{P}_{1}}\right)^{2}}$

Pers. 7

Keterangan:

$\mathrm{P}_{\mathrm{i}}=$ data observasi (data sebenarnya).

$\mathrm{Q}_{\mathrm{i}}=$ data perkiraan (data hasil estimasi).

$\mathrm{i}=$ data observasi rata-rata.

$\mathrm{N}=$ jumlah data.

Tabel 1: Kriteria Nilai Nash-Sutcliffe Efficiency (NSE)

\begin{tabular}{cc}
\hline NSE & Intrepretasi \\
\hline \hline NSE $>0,75$ & Baik \\
$0,36<$ NSE $<0,75$ & Memenuhi \\
NSE $<0,36$ & Tidak Memenuhi \\
\hline
\end{tabular}

b. Koefisien Korelasi (R)

Analisis korelasi ialah salah satu metode statistik yang biasa digunakan dalam mengetahui kuatnya hubungan antara dua variabel [16].

$\mathrm{R}=\frac{\mathrm{N} \sum_{\mathrm{i}=1}^{\mathrm{N}} \mathrm{P}_{\mathrm{i}} \mathrm{Q}_{\mathrm{i}}-\sum_{\mathrm{i}=1}^{\mathrm{N}} \mathrm{P}_{\mathrm{i}} \times \sum_{\mathrm{i}=1}^{\mathrm{N}} \mathrm{Q}_{\mathrm{i}}}{\sqrt{\mathrm{N} \sum_{\mathrm{i}=1}^{\mathrm{N}} \mathrm{P}_{\mathrm{i}}^{2}-\left(\sum_{\mathrm{i}=1}^{\mathrm{N}} \mathrm{P}_{\mathrm{i}}\right)^{2}} \sqrt{\mathrm{N} \sum_{\mathrm{i}=1}^{\mathrm{N}} \mathrm{Q}_{\mathrm{i}}^{2}-\left(\sum_{\mathrm{i}=1}^{\mathrm{N}} \mathrm{Q}_{\mathrm{i}}\right)^{2}}}$

Pers. 8

Keterangan:

$\mathrm{P}_{\mathrm{i}}=$ data observasi (data penakar hujan).

$\mathrm{Q}_{\mathrm{i}}=$ data perkiraan (data Satelit hasil estimasi).

$\mathrm{N}=$ jumlah data.

Tabel 2: Kriteria Nilai Koefisien Korelasi

\begin{tabular}{cc}
\hline $\mathrm{R}$ & Intrepretasi \\
\hline \hline $0-0,19$ & Sangat Rendah \\
$0,20-0,39$ & Rendah \\
$0,40-0,59$ & Sedang \\
$0,60-0,79$ & Kuat \\
$0,81-1$ & Sangat Kuat \\
\hline
\end{tabular}

c. Root Mean Squared Error (RMSE)

RMSE menunjukkan tingkat kesalahan atau error [9]. Semakin kecil nilai RMSE maka akan semakin kecil juga perbedaan diantara keduanya sehingga hasil dari nilai estimasi TRMM akan semakin akurat [17]. 
RMSE $=\sqrt{\frac{\sum_{\mathrm{i}=1}^{\mathrm{N}}\left(\mathrm{P}_{\mathrm{i}}-\mathrm{Q}_{\mathrm{i}}\right)^{2}}{\mathrm{~N}}}$

Pers. 9

Keterangan:

$\mathrm{P}_{\mathrm{i}}=$ data observasi (data penakar hujan).

$\mathrm{Q}_{\mathrm{i}}=$ data perkiraan (data Satelit hasil estimasi).

$\mathrm{N}=$ jumlah data.

d. Kesalahan Relatif (KR)

Uji ini bertujuan agar tahu perbandingan antara besarnya nilai dari variabel satu terhadap variabel lainnya yang dianggap sebagai patokan variabel sebenarnya [18].

$\mathrm{KR}=\frac{\sum_{\mathrm{i}=1}^{\mathrm{N}}\left(\mathrm{P}_{\mathrm{i}}-\mathrm{Q}_{\mathrm{i}}\right)}{\sum_{\mathrm{i}=1}^{\mathrm{N}} \mathrm{P}_{\mathrm{i}}} \times 100 \%$

Pers. 10

Keterangan:

$\mathrm{P}_{\mathrm{i}}=$ data observasi (data penakar hujan).

$\mathrm{Q}_{\mathrm{i}}=$ data perkiraan (data Satelit hasil estimasi).

$\mathrm{N}=$ jumlah data.

\section{Hasil dan Pembahasan}

Penelitian ini menggunakan periode bulanan, 15 harian dan 10 harian. Pembagian dari periode ini tujuannya agar tahu kestabilan data apabila datanya semakin fluktuatif, karena data harian tentu variabilitasnya lebih tinggi apabila dibandingkan dengan data bulanan. Sebelum dilakukan analisis validasi, data terlebih dahulu diuji kualitas data karena dianggap memiliki kualitas statistik yang lebih baik. Uji kualitas data berupa uji konsistensi serta uji stasioner (Uji-F serta Uji-t). Adapun hasil dari kedua uji tersebut dari data pos penakar hujan dan TRMM memperoleh hasil yang konsisten dan homogen.

Selanjutnya, karena data TRMM yang telah diunduh berupa data curah hujan luasan, maka perlu dilakukan transformasi data curah hujan pos penakar hujan menjadi data curah hujan rerata wilayah agar hasilnya lebih mendekati. Metode perhitungan curah hujan rerata wilayah berupa Polygon Thiessen karena metode ini pada prinsipnya menghitung bobot dari setiap luasan hasil dari pos penakar hujan yang mewakili luasan di sekitarnya, hasil dari Polygon Thiessen ditampilkan pada Gambar 2.

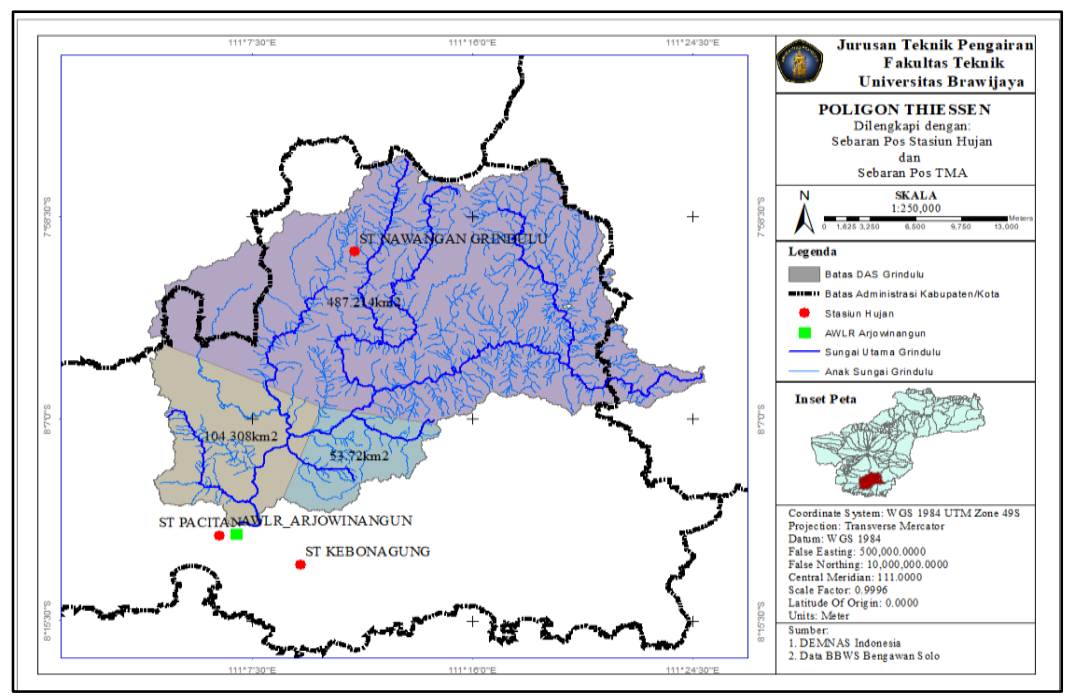

Gambar 2: Polygon Thiessen DAS Grindulu 
Kemudian setelah didapatkan luas pengaruh dari masing-masing penakar hujan, selanjutnya dilakukan perhitungan seberapa besar faktor pengaruh penakar hujan tersebut menggunakan metode poligon thiessen, selengkapnya berada dalam Tabel 3 dibawah ini

Tabel 3: Nilai Pengaruh Luas Pos Penakar Hujan (Kr)

\begin{tabular}{cccc}
\hline Pos Penakar Hujan & Luas $\left(\mathrm{km}^{2}\right)$ & $\mathrm{Kr}$ & Luas Pengaruh (\%) \\
\hline \hline Kebonagung & 53.720 & 0.083 & 8,3 \\
Nawangan Grindulu & 487.214 & 0.755 & 75,5 \\
Pacitan & 104.308 & 0.162 & 16,2 \\
\hline Jumlah & 645.242 & 1.000 & 100 \\
\hline
\end{tabular}

Dapat disimpulkan dari Tabel 3 didapatkan luas pengaruh dari Stasiun Kebonagung sebesar 8,3\%, Stasiun Nawangan Grindulu sebesar 75,5\% dan Stasiun Pacitan sebesar 16,2\%. Meskipun Stasiun Kebonagung memberikan pengaruh yang kecil tetapi tetap digunakan karena pada dasarnya masih memberikan luas pengaruh hujan di wilayah Stasiun Kebonagung sesuai dengan prinsip dari poligon thiessen yang mempertimbangkan bobot dari masing-masing luasan yang terbentuk.

\subsection{Hasil Validasi Data TRMM Tidak Terkoreksi}

Analisis ini memakai periode bulanan, 15 harian, dan 10 harian serta panjang datanya selama 10 tahun. Rentang data yang dipakai untuk analisis validasi data tidak terkoreksi ini adalah 10 tahun, 3 tahun, 2 tahun, serta 1 tahun. Data langsung dilakukan uji validasi dengan menggunakan empat metode dan hasil dari perhitungan validasi data tidak terkoreksi berada pada Tabel 4 .

Tabel 4: Hasil Analisis Validasi Data TRMM Tidak Terkoreksi

\begin{tabular}{|c|c|c|c|c|c|c|c|}
\hline \multirow{2}{*}{\multicolumn{2}{|c|}{ Periode }} & \multirow{2}{*}{ RMSE } & \multicolumn{2}{|r|}{ NSE } & \multirow{2}{*}{$\mathrm{KR}$} & \multicolumn{2}{|r|}{$\mathrm{R}$} \\
\hline & & & Nilai & Interpretasi & & Nilai & Interpretasi \\
\hline \multirow{4}{*}{10 Harian } & 10 Tahun & 56.956 & 0.264 & Tidak Memenuhi & 0.254 & 0.679 & Kuat \\
\hline & 3 Tahun & 57.331 & 0.422 & Memenuhi & 0.363 & 0.824 & Sangat Kuat \\
\hline & 2 Tahun & 48.808 & 0.554 & Memenuhi & 0.356 & 0.845 & Sangat Kuat \\
\hline & 1 Tahun & 40.395 & 0.674 & Memenuhi & 0.293 & 0.884 & Sangat Kuat \\
\hline \multirow{4}{*}{15 Harian } & 10 Tahun & 65.905 & 0.488 & Memenuhi & 0.243 & 0.801 & Sangat Kuat \\
\hline & 3 Tahun & 73.286 & 0.536 & Memenuhi & 0.361 & 0.868 & Sangat Kuat \\
\hline & 2 Tahun & 64.474 & 0.610 & Memenuhi & 0.350 & 0.877 & Sangat Kuat \\
\hline & 1 Tahun & 49.361 & 0.743 & Memenuhi & 0.290 & 0.908 & Sangat Kuat \\
\hline \multirow{4}{*}{ Bulanan } & 10 Tahun & 100.780 & 0.631 & Memenuhi & 0.257 & 0.883 & Sangat Kuat \\
\hline & 3 Tahun & 112.099 & 0.678 & Memenuhi & 0.387 & 0.944 & Sangat Kuat \\
\hline & 2 Tahun & 102.600 & 0.695 & Memenuhi & 0.362 & 0.929 & Sangat Kuat \\
\hline & 1 Tahun & 78.415 & 0.799 & Baik & 0.290 & 0.944 & Sangat Kuat \\
\hline
\end{tabular}

Berdasarkan dari hasil analisis validasi dari data TRMM tidak terkoreksi dengan data pos penakar hujan dapat ditarik kesimpulan bahwa hasil validasi hampir menunjukkan hasil yang cukup baik, tetapi perlu dilakukan analisis lanjutan dengan mengoreksi data curah hujan TRMM sebelum divalidasi dengan data curah hujan pos penakar hujan untuk tujuan mendapatkan data yang lebih baik lagi karena hasil validasi data curah hujan TRMM tidak terkorkesi masih kurang maksimal karena masih terapat intrepetasi nilai NSE yang "Tidak 
Memenuhi" serta nilai RMSE yang masih sangat tinggi serta intrepetasi yang "Kuat" dibandingkan yang lainnya, hasil tersebut terdapat pada periode 10 harian rentang validasi langsung 10 tahun. Berikut disajikan grafik hasil validasi tidak terkoreksi dari masingmasing periode dan rentang tahun pada Gambar 3.

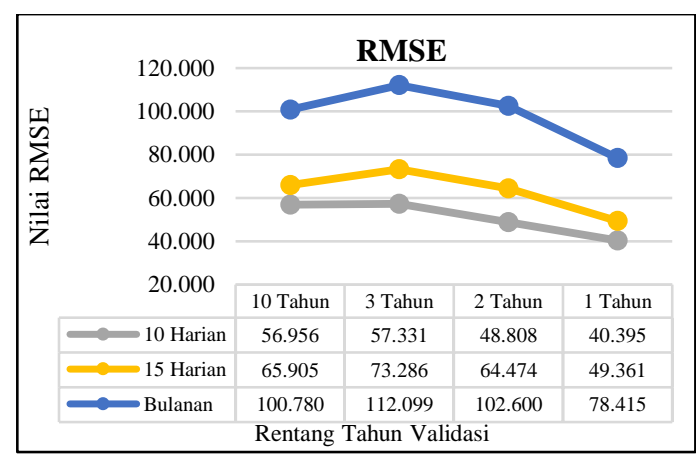

(a)

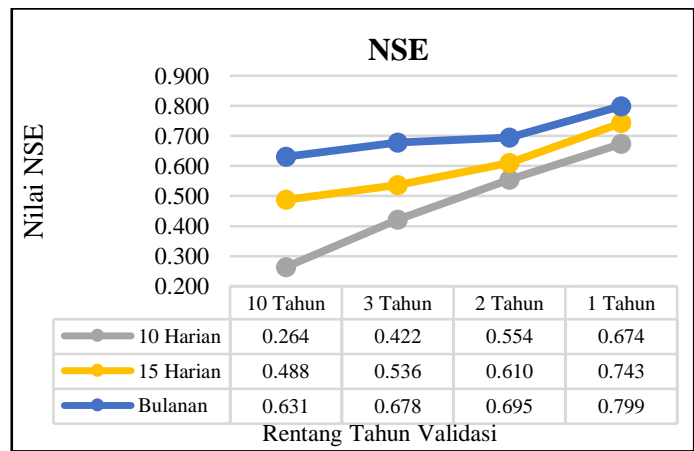

(c)

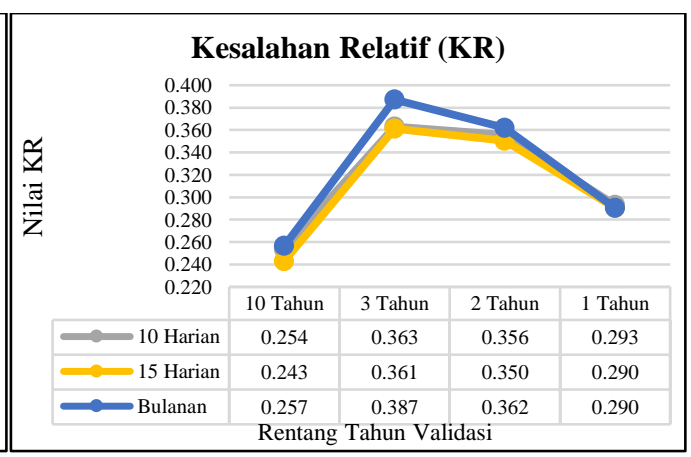

(b)

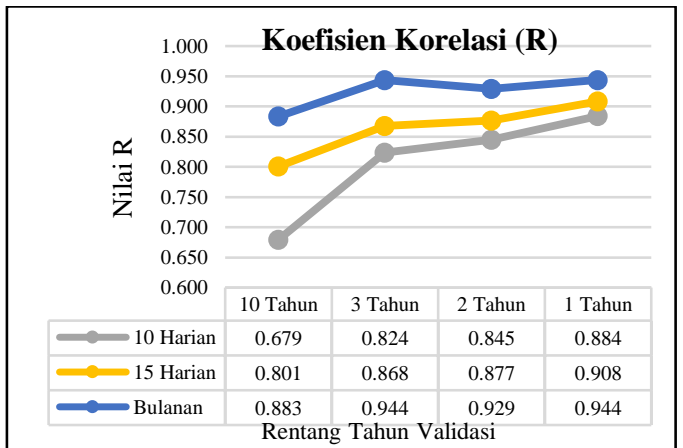

(d)

\section{Gambar 3: Pola Hasil Validasi Data TRMM Tidak Terkoreksi (a) RMSE (b) Kesalahan Relatif (c) NSE (d) Koefisien Korelasi}

Dari Gambar 3 terdapat pola yang dihasilkan dari masing-masing parameter validasi data TRMM tidak terkoreksi. Pada Gambar 3 (a) periode bulanan memiliki nilai RMSE yang paling tinggi dikarenakan pada periode tersebut dihasilkan data hujan yang besar nilainya sehingga berpotensi menghasilkan nilai RMSE yang besar pula, trend dari keempat rentang tahun dari masing-masing periode menghasilkan nilai RMSE tertinggi pada rentang 3 tahun validasi. Gambar 3 (b) juga menunjukkan bahwa periode bulanan juga menghasilkan kesalahan relatif yang tertinggi dan juga trend dari keempat rentang tahun dari masing-masing periode menghasilkan nilai kesalahan relatif tertinggi pada rentang 3 tahun validasi. Gambar 3 (c) menghasilkan nilai NSE yang paling tinggi juga berada pada periode bulanan yang artinya pada periode tersebut hasilnya paling baik karena mendekati satu, trend dari keempat rentang tahun dari masing-masing periode menghasilkan nilai NSE yang meningkat kemudian nilai NSE tertinggi terdapat pada rentang 1 tahun validasi. Sementara itu, Gambar 3 (d) menunjukkan bahwa nilai koefisien korelasi yang tertinggi juga terdapat pada periode bulanan dengan trend yang fluktuatif, dimana puncak koefisien korelasi tertinggi terdapat pada rentang validasi 3 tahun. Maka, dapat diambil kesimpulan periode bulanan menghasilkan nilai yang paling tinggi pada setiap parameter validasi, pada hal ini belum dapat ditarik kesimpulan bahwa periode bulanan adalah yang paling baik karena masih menghasilkan nilai RMSE dan nilai kesalahan relatif yang tinggi, sementara 
itu hasil dikatakan baik jika nilai RMSE dan kesalahan relatifnya rendah kemudian nilai NSE dan koefisien korelasinya tinggi.

\subsection{Hasi Validasi Data TRMM Terkoreksi}

Untuk mendapatkan data hujan TRMM terkoreksi sebelum dilakukan uji validasi, terlebih dahulu dilakukan kalibrasi data. Proses kalibrasi data dilakukan dengan cara membagi datanya menjadi dua bagian kelompok, komposisi perbandingannya yakni, 7:3, $8: 2$, serta 9:1.

Faktor koreksi yang digunakan dalam persamaan regresi dihasilkan melalui proses kalibrasi dimana persamaan yang dihasilkan dari scatter plot yang disebut sebagai faktor koreksi, dengan memilih koefisien korelasi $(\mathrm{R})$ terbesar yang terpilih dari setiap persamaan regresi tersebut. Pada tahap kalibrasi nilai $\mathrm{R}$ dihitung seusai dengan rentang tahun yang digunakan, sama halnya seperti validasi juga dihitung nilai $R$, kemudian jika jenis persamaan yang terpilih antara kedua tahap tersebut sejenis maka dapat langsung digunakan, namun jika jenis persamaan yang terpilih berbeda dilakukan perhitungan nilai NSE di antara kedua persamaan tersebut untuk menentukan jenis persamaan akhir yang terpilih menggunakan rentang tahun pada tahap validasi. Tahap validasi menggunakan rentang tahun di luar periode kalibrasi. Berikut hasil sinkronisasi nilai $\mathrm{R}$ dan jenis akhir persamaan terbaik yang terpilih untuk mengkoreksi data TRMM disajikan pada Tabel 5.

Tabel 5: Hasil Sinkronisasi Jenis Persamaan Regresi Akhir Terpilih

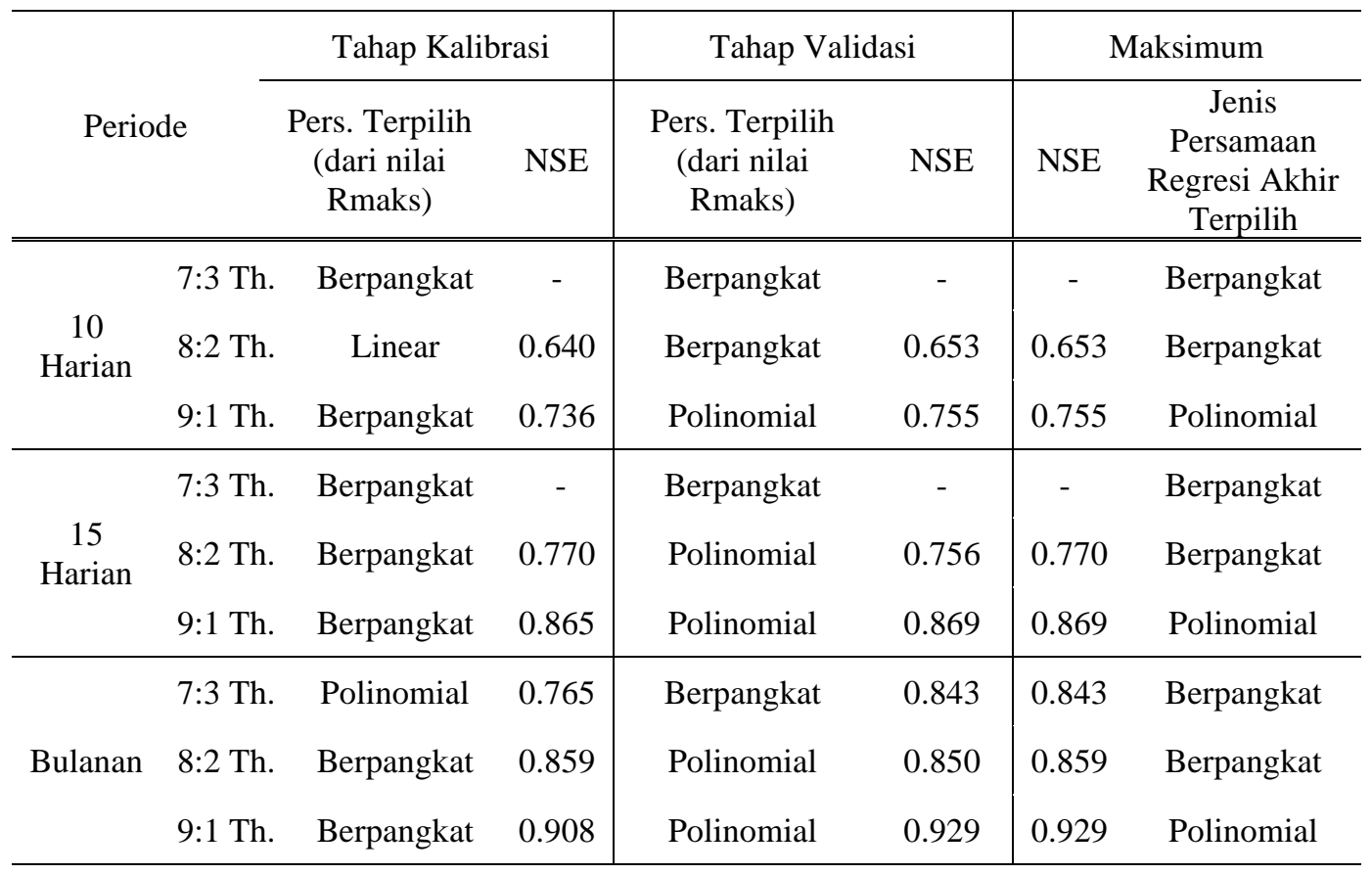

Persamaan yang sudah terpilih berdasarkan nilai NSE yang tertinggi masing-masing periode diikuti dengan komposisi tahun yang digunakan untuk kalibrasi dan validasi data didominasi oleh persamaan berpangkat, hanya pada komposisi 9 tahun kalibrasi dan1 tahun validasi yang dihasilkan jenis persamaannya polinomial setiap periodenya. Selanjutnya dilakukan perhitungan validasi dari jenis persamaan yang sudah terpilih tersebut dengan empat metode hasilnya berada pada Tabel 6. 
Tabel 6: Hasil Perhitungan Validasi Data Terkoreksi

\begin{tabular}{|c|c|c|c|c|c|c|c|c|c|}
\hline \multirow{2}{*}{\multicolumn{2}{|c|}{ Periode }} & \multirow{2}{*}{\multicolumn{2}{|c|}{$\begin{array}{c}\text { Jenis Persamaan Regresi Akhir } \\
\text { Terpilih }\end{array}$}} & \multirow{3}{*}{$\begin{array}{c}\text { RMSE } \\
53.671\end{array}$} & \multicolumn{2}{|c|}{ NSE } & \multirow{3}{*}{$\begin{array}{c}\text { KR } \\
0.301\end{array}$} & \multicolumn{2}{|r|}{$\mathrm{R}$} \\
\hline & & & & & \multirow{2}{*}{$\begin{array}{c}\text { Nilai } \\
0.493\end{array}$} & \multirow{2}{*}{$\begin{array}{l}\text { Interpretasi } \\
\text { Memenuhi }\end{array}$} & & \multirow{2}{*}{$\begin{array}{l}\text { Nilai } \\
0.829\end{array}$} & \multirow{2}{*}{$\begin{array}{c}\text { Interpretasi } \\
\text { Sangat Kuat }\end{array}$} \\
\hline \multirow{3}{*}{ Harian } & $3 \mathrm{Th}$. & Berpangkat & $5.7277 x^{0.6356}$ & & & & & & \\
\hline & 2 Th. & Berpangkat & $6.8637 \mathrm{x}^{0.6042}$ & 43.073 & 0.653 & Memenuhi & 0.271 & 0.869 & Sangat Kuat \\
\hline & $1 \mathrm{Th}$. & Polinomial & $-0.0022 x^{2}+1.4365 x$ & & 0.755 & Baik & & 0.901 & Kuat \\
\hline \multirow{3}{*}{$\begin{array}{c}15 \\
\text { Harian }\end{array}$} & $3 \mathrm{Th}$. & Berpangkat & $2.7784 x^{0.8317}$ & & 0.695 & Memenuhi & & 0.882 & Kuat \\
\hline & 2 Th. & Berpangkat & $3.2653 \mathrm{x}^{0.8062}$ & & 0.770 & Baik & & 0.898 & Sangat Kuat \\
\hline & $1 \mathrm{Th}$. & Polinomial & $-0.0016 x^{2}+1.502 x$ & 35.269 & 0.770 & Baik & 0.141 & 0.943 & Sangat Kuat \\
\hline \multirow{3}{*}{$\begin{array}{l}\text { Bulan- } \\
\text { an }\end{array}$} & 3 Th. & Berpangkat & $1.9252 \mathrm{x}^{0.9256}$ & 78.293 & 0.843 & Baik & 0.214 & 0.947 & Sangat Kuat \\
\hline & 2 Th. & Berpangkat & $2.529 \mathrm{x}^{0.8842}$ & 69.644 & 0.859 & Baik & 0.137 & 0.937 & Sangat Kuat \\
\hline & 1 Th. & Polinomial & $-0.0011 x^{2}+1.5959 x$ & 46.480 & 0.929 & Baik & 0.089 & 0.969 & Sangat Kuat \\
\hline
\end{tabular}

Dihasilkan dari keempat parameter validasi tersebut terdapat perbedaan dengan validasi dari data TRMM yang tidak terkoreksi, yaitu hasil validasi data TRMM yang terkoreksi nilainya jauh lebih baik. Dapat ditinjau dari nilai RMSE dan Kesalahan Relatifnya setiap periode dan rentang tahun mengalami penurunan. Sementara itu nilai NSE dan koefisien korelasinya mengalami peningkatan yang hampir mendekati satu. Dimana jika nilai-nilai dari parameter validasi tersebut dijadikan grafik untuk melihat kecenderungan pola dari setiap periodenya maka terdapat pada Gambar 4.

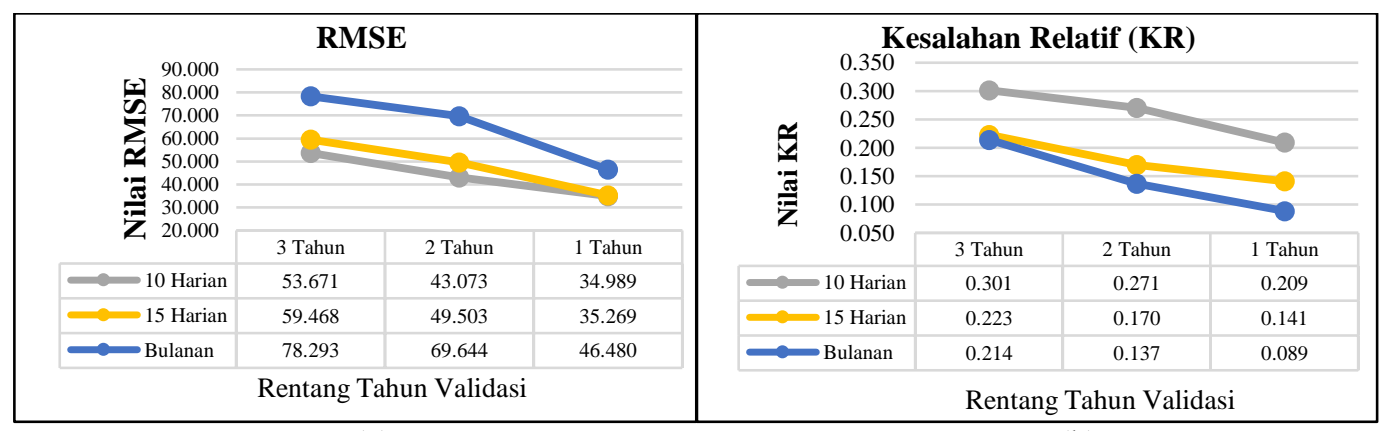

(a)

(b)

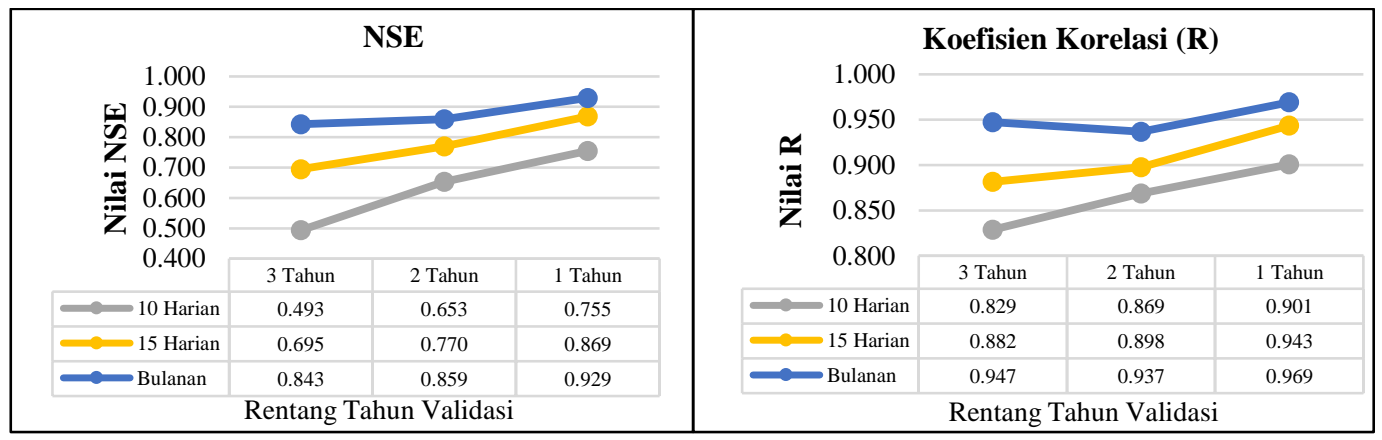

(c)

(d)

Gambar 4: Pola Hasil Validasi Data TRMM Terkoreksi (a) RMSE (b) Kesalahan Relatif (c) NSE (d) Koefisien Korelasi

Dari Gambar 4 tersebut juga terdapat pola yang dihasilkan dari masing-masing parameter validasi data TRMM terkoreksi. Pada Gambar 4 (a) periode bulanan memiliki nilai RMSE tertinggi dikarenakan pada periode tersebut dihasilkan data hujan yang besar nilainya sehingga berpotensi menghasilkan nilai RMSE yang besar pula, trend dari ketiga rentang tahun masing-masing periode mengalami penurunan dari validasi 3 tahun menuju 
validasi 1 tahun. Gambar 4 (b) menunjukkan bahwa periode bulanan memiliki nilai kesalahan relatif yang paling rendah dan juga trend dari ketiga rentang tahun dari masingmasing periode mengalami penurunan dari validasi 3 tahun menuju validasi 1 tahun. Gambar 4 (c) menghasilkan nilai NSE yang paling tinggi juga terdapat pada periode bulanan yang artinya pada periode tersebut hasilnya paling baik karena mendekati satu, trend dari ketiga rentang tahun dari masing-masing periode menghasilkan nilai NSE yang meningkat dari validasi 3 tahun menuju validasi 1 tahun yang artinya nilai NSE tertinggi terdapat pada rentang 1 artinya pada validasi 1 tahun nilainya paling baik. Gambar 4 (d) menunjukkan bahwa nilai koefisien korelasi yang tertinggi juga terdapat pada periode bulanan dengan trend meningkat dari validasi 3 tahun menuju validasi 1 tahun yang artinya nilai $\mathrm{R}$ tertinggi terdapat pada rentang 1 tahun validasi dimana pada validasi 1 tahun hubungan antara data TRMM dan data observasi adalah "Sangat Kuat". Karena periode bulanan nilai NSE dan R-nya paling tinggi terutama pada validasi 1 tahun artinya hasil tersebut paling baik, didukung dengan kesalahan relatif periode bulanan validasi 1 tahunlah yang nilainya paling kecil. Sehingga dapat disimpulkan bahwa data TRMM terkoreksi menghasilkan nilai validasi yang lebih baik dibandingkan data TRMM tidak terkoreksi.

\section{Kesimpulan}

Hasil dari validasi data curah hujan pos penakar hujan dengan data Satelit TRMM di DAS Grindulu menunjukkan bahwa validasi data TRMM terkoreksi menghasilkan nilai yang lebih baik daripada nilai validasi data TRMM tidak terkoreksi, ditinjau dari nilai RMSE dan Kesalahan Relatif yang cenderung menurun sedangkan untuk nilai NSE dan Koefisien Korelasi mengalami kenaikan yang artinya nilai dari data TRMM terkoreksi dan data curah hujan pos hujan semakin baik dan memiliki hubungan yang semakin kuat.

Berdasarkan metode RMSE, Kesalahan Relatif, NSE dan Koefisien Korelasi juga dihasilkan bahwa dengan komposisi perbandingan datanya adalah 9:1 (9 tahun data untuk kalibrasi dan 1 tahun data untuk validasi) pada setiap periode terutama periode bulanan nilainya merupakan yang paling baik, dengan hasil nilai $\mathrm{NSE}=0,929 ; \mathrm{R}=0,969$; RMSE $=46,48$ dan Kesalahan Relatif $=8,9 \%$ dimana nilai NSE dan $\mathrm{R}$ yang mendekati satu yang artinya memiliki hasil yang baik serta hubungan yang sangat kuat. Sementara itu untuk nilai RMSEnya mengalami penurunan dibandingkan data TRMM tidak terkoreksi, dan juga dihasilkan nilai kesalahan relatif yang sangat kecil pada periode bulanan dengan komposisi 9 tahun kalibrasi dan 1 tahun validasi.

Sehingga dapat disimpulkan bahwa data curah hujan Satelit TRMM di DAS Grindulu dapat digunakan sebagai data alternatif hidrologi pengganti data curah hujan pos penakar hujan, tetapi alangkah lebih baik data tersebut dilkukan koreksi terlebih dahulu.

\section{Daftar Pustaka}

[1] M. D. Syaifullah, "Validasi Data Trmm Terhadap Data Curah Hujan Validation of Trmm Data With Actual Rainfall Data in Three Watersheds in Indonesia," pp. 109118, 2014.

[2] R. A. Noor, “p-ISSN 1978-8096 e-ISSN 2302-3708," Pemanfaat. DATA SATELIT Trop. RAINFALL Meas. Mission UNTUK PEMETAAN Zo. Agroklim. OLDEMAN DI KALIMANTAN SELATAN, vol. 12, no. 3, pp. 267-281, 2016. 
[3] Soewarno, Hidrologi Aplikasi Metode Statistik Jilid 1, vol. 1. Bandung, 1995.

[4] W. Willy, B. A. Riyanto, D. Yudianto, and A. Wicaksono, "Application of TRMM Data to the Analysis of Water Availability and Flood Discharge in Duriangkang Dam," J. Civ. Eng. Forum, vol. 6, no. 1, p. 79, 2020, doi: 10.22146/jcef.51521.

[5] R. A. Noor, et.al, "Pemanfaatan Data Satelit Tropical Rainfall Measuring Mission (Trmm) Untuk Pemetaan Zona Agroklimat Oldeman Di Kalimantan Selatan," EnviroScienteae, vol. 12, no. 3, p. 267, 2016, doi: 10.20527/es.v12i3.2452.

[6] A. Zubaidah, "Analisis Perubahan Curah Hujan Satelit Tropical Measuring Mission ( Trmm ) Tahun 2009 Dan Tahun 2010,” Teknologi, 2012.

[7] D. W. Pratiwi, J. Sujono, and A. P. Rahardjo, "Evaluasi Data Hujan Satelit Untuk Prediksi Data Hujan Pengamatan Menggunakan Cross Correlation," Semin. Nas. Sains dan Teknol., no. November, pp. 1-2, 2017.

[8] S. B. Soeryamassoeka, R. W. Triweko, and D. Yudianto, "VALIDATION OF TROPICAL RAINFALL MEASURING MISSION," vol. 11, no. 2, pp. 125-131, 2020, doi: 10.33736/jcest.2267.2020.

[9] Indarto, Hidrologi Dasar Teori dan Contoh Aplikasi Model Hidrologi. Jember: Bumi Aksara, 2010.

[10] H. Maulana, E. Suhartanto, and D. Harisuseno, "Analysis of Water Availability Based on Satellite Rainfall in the Upper Brantas River Basin," Int. Res. J. Adv. Eng. Sci., vol. 4, no. 2, pp. 393-398, 2019.

[11] Soewarno, Hidrologi Aplikasi Metode Statistik Jilid 2. Bandung: NOVA, 1995.

[12] N. F. Rahma, E. Suhartanto, and D. Harisuseno, "Validasi Data Curah Hujan TRMM dengan Pos Stasiun Hujan di Sub DAS Brantas," p. 2, 2019, [Online]. Available: https://jurnalpengairan.ub.ac.id/index.php/jtp.

[13] D. N. Moriasi, et.al, "Model Evaluation Guidelines for Systematic Quantification of Accuracy in Watershed Simulations," Trans. ASABE, vol. 50, no. 3, pp. 885-900, 2007, doi: 10.13031/2013.23153.

[14] M. Atthahirah, D. Harisuseno, and E. Suhartanto, "Validasi Data Curah Hujan TRMM dengan Pos Stasiun Hujan di Sub DAS Bango," p. 2, 2019, [Online]. Available: http://repository.ub.ac.id/170849/.

[15] N. M. Candra, E. Suhartanto, and D. Harisuseno, "VALIDASI DATA CURAH HUJAN TRMM SEBAGAI ALTERNATIF DATA HIDROLOGI DI SUB-DAS LESTI,” 2019, [Online]. Available: https://jurnalpengairan.ub.ac.id/index.php/jtp.

[16] C. Asdak, "Hidrologi dan Pengelolaan Daerah Aliran Sungai." Gadjah Mada University Press, Yogyakarta, 2007.

[17] M. D. Syaifullah, "Validasi Data Trmm Terhadap Data Curah Hujan Aktual Di Tiga Das Di Indonesia," J. Meteorol. dan Geofis., vol. 15, no. 2, pp. 109-118, 2014, doi: 10.31172/jmg.v15i2.180.

[18] S. Lufi, S. Ery, and R. Rispiningtati, "Hydrological Analysis of TRMM Data in Lesti Sub Watershed," Civ. Environ. Sci., vol. 003, no. 01, pp. 018-030, 2020, doi: 10.21776/ub.civense.2020.00301.3. 